\title{
Retraction Note: Coastline climate environment and coastal city English smart teaching simulation based on GIS system
}

\section{Li Hongxia ${ }^{1}$}

Published online: 22 November 2021

(c) Saudi Society for Geosciences 2021

\section{Retraction Note: Arabian Journal of Geosciences (2021) 14: 1481} https://doi.org/10.1007/s12517-021-07738-4

The Editor-in-Chief and the Publisher have retracted this article because the content of this article is nonsensical. The peer review process was not carried out in accordance with the Publisher's peer review policy. The author has not responded to correspondence regarding this retraction.

The original article can be found online at https://doi.org/10.1007/ s12517-021-07738-4.

Li Hongxia

Lihongxia12300@163.com

1 School of Business English, Hunan International Business Vocational College, Changsha 410200, Hunan, China 